\title{
FORECASTING ACCURACY AND STRUCTURAL STABILITY OF THE ECONOMIC BASE MODEL
}

\author{
Paul E. Polzin, Kent Connaughton, Con H Schallau, and James T. Sylvester*
}

The economic base theory was formulated more than 50 years ago. Even though it has been integrated into a theory of regional growth, it is viewed primarily as one tool of regional impact analysis (Lane, 1966; Tiebout, 1962). Today, the economic base model is used primarily to estimate and evaluate impacts of specified projects in a specific region. For example, the impact of an increase in the timber harvest, a new military installation, or the closure of a manufacturing plant may be analyzed by estimating the economic base multiplier for the relevant locality, computing basic activity changes, and then calculating derivative activity changes. Local area impact analysis often is a component of the permit granting or review process conducted by government agencies.

Although much has been written about the economic base model, this literature provides little help for the analyst who must estimate the impact of a specified project. McNulty (1977) concluded that the economic base theory fits the facts well in the long run, but not the short run. His study, however, used data for changes computed for various periods in a cross section of Standard Metropolitan Statistical Areas. The findings may not be relevant for a specific community.

Garrison (1972) estimated economic base multipliers for small rural communities. He based his estimates, however, on the ratio of changes in derivative to basic activity between two years, rather than on a more sophisticated procedure that takes into account more than two data points. Giarratani and $\mathrm{McNelis}$ (1980) used time series analysis to conclude that there is "little causal interaction of the kind suggested by economic base theory between export and derivative income." They analyzed data for states, although they admit that thesemay not be functional regions, and their 16 annual observations may be insufficient for the time series methods they employed.

A number of authors have analyzed employment data and found time lags between changes in the basic sector and the resulting changes in the derivative section (Luttrell

\footnotetext{
*Professor and Director, Bureau of Business and Economic Research, University of Montana; research economist, USDA Forest Service, Pacific Northwest Forest and Range Experiment Station, Portland, Oregon; research economist, USDA Forest Service, Pacific Northwest Forest and Range Experiment Station, Corvallis, Oregon; and statistician, Bureau of Business and Economic Research, University of Montana.
}

and Gray, 1970; Henry and Nyankori, 1981; Bender and Parcels, 1983). These studies analyzed major metropolitan areas or, if they examined smaller communities, they used a combination of time series and cross section data so that the findings may not apply to a specific locality. Further, a multi-equation labor market specification may be required to estimate economic base models correctly using employment data (Polzin, 1973, 1977).

Despite the forecasting and impact analysis emphasis, there have been no attempts to evaluate the economic base model on the basis of its predictions. Simply comparing the projections reported in impact studies with actual data may provide unreliable tests because the specified project may be only one of many sources of local area change. This paper examines the performance of the economic base model for four timber-dependent communities in the Pacific Northwest, using the accuracy of $e x$ post forecasts and other statistical measures.

\section{The Study Areas}

Four communities were chosen for analysis-two in Montana and two in Oregon. Each consists of a single county, or in one case, two contiguous counties with twin cities. All four communities are resource-dependent: their basic sectors depend substantially on natural resources. The four communities are pictured in Figure 1. These communities have a number of features in common.

1. Each is a functional region. As is typical of rural western communities, each county (or contiguous counties) is dominated by a single urban area containing most of the population and commercial activity. For Douglas County, Oregon, the central city is Roseburg; for LinnBenton counties, Corvallis and Albany; for Flathead County, Montana, Kalispell is the central city; that for Missoula County is Missoula. The commuting of workers is not a significant problem in any of the communities.

2. All are relatively small and typical of communities chosen for economic impact studies. ${ }^{1}$ None of these communities are Metropolitan Statistical Areas. In 1980, Douglas County (Roseburg) had a population of about 93,700 ; 
Location of the Four Timber-Dependent Communities

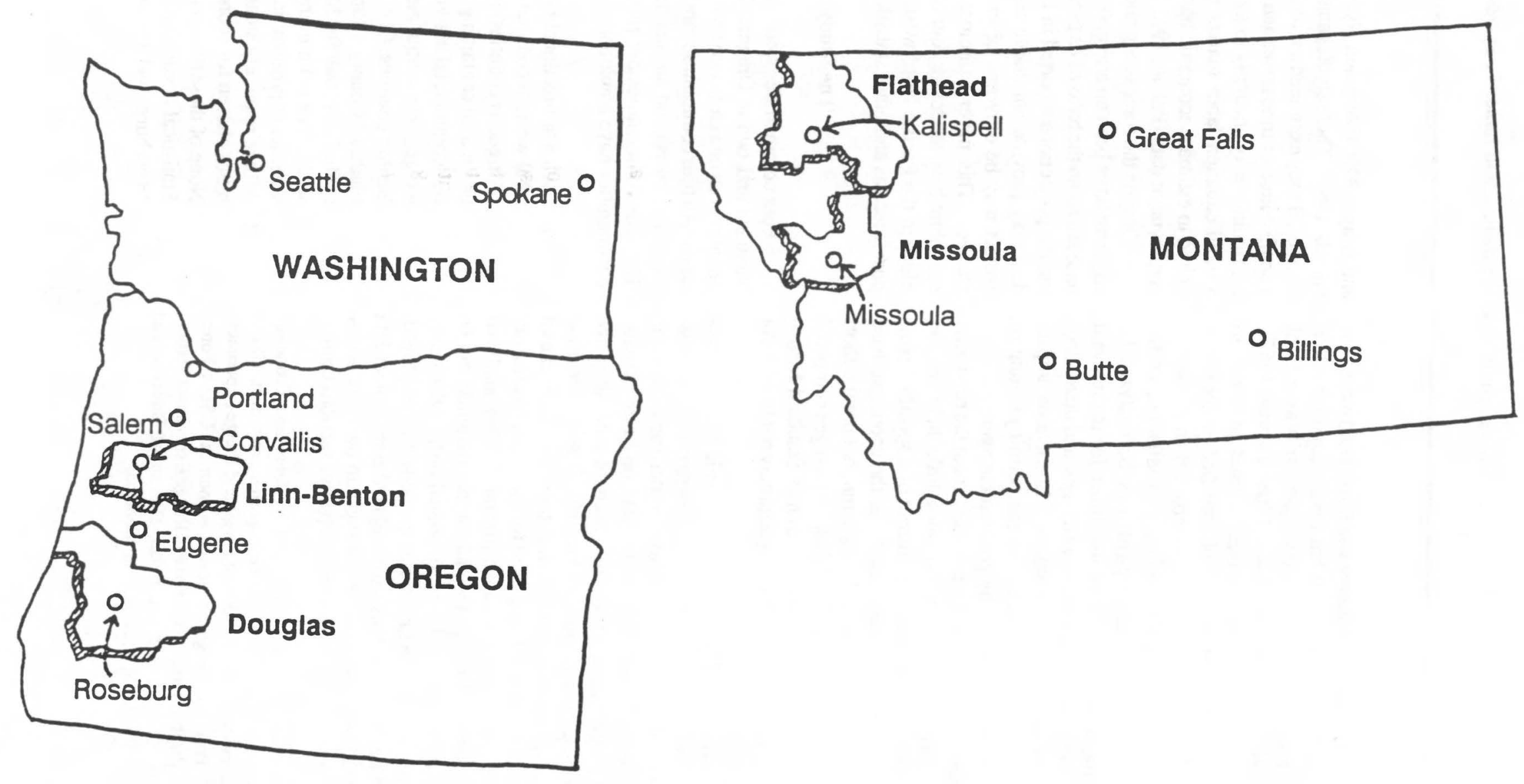


Linn-Benton counties (Corvallis-Albany) had approximately 157,700 residents; Flathead County had 52,000 people; and Missoula County had a population of roughly 76,000 .

3. All four grew quickly. In population and per capita income, the four communities increased faster than their respective statewide averages in the 1970s. All four experienced net inmigration between 1970 and 1980.

4. The export (basic) industries in each community have been identified and quantified. ${ }^{2}$ Although accurate estimates of the economic base have long been a problem in economic base analysis, these four communities were studied earlier and each two- or three-digit SIC category was classified as basic or derivative (Schallau and Polzin, 1983). A summary of the basic industries in each community is presented in Appendix Tables 1 to 4.

5. In each community, the wood products industry is a major export industry. It dominates the economic base with no more than one other industry. ${ }^{3}$ In Douglas County, the wood products industry alone accounts for about 75 percent of the economic base; in Linn-Benton counties, the wood products industry and Oregon State University combined account for about two-thirds of basic activity; in Flathead County, wood products and an aluminum refinery represent about 70 percent of the total for all basic industries; and in Missoula County, wood products and the University of Montana represent 67 percent of the economic base.

\section{The Data}

The economic base model was evaluated using a time series of quarterly data for wages and salaries in each of the four communities. This is an income version of the economic base model. Although the theory is based on propensities to spend and other income expenditure relations, and many authors admit that income is the appropriate measure of economic activity, most empirical applications of the economic base model have used employment data (Thompson, 1959; Tiebout, 1962). The use of employment may have been acceptable in earlier years when no other data were available, but it is inferior to income for economic base models (Polzin, 1977).

The income measure used here was based on wages and salaries of workers covered by unemployment insurance (UI) in Montana and Oregon plus estimates for key non-covered industries (such as the federal government and certain other state govemment agencies) derived from other sources. To maintain consistency, certain industries were excluded if data were not available for the entire period (i.e., if an industry was covered by unemployment insurance for only a portion of the study period). ${ }^{4}$ The data include all firms with one or more employees.

A time series of 96 observations was available for each community, from the first quarter of 1961 through the fourth quarter of 1984, hereafter denoted as 1961Q1 through 1984 Q4. The data were not adjusted seasonally and are in current dollars.

The income measure used here is less comprehensive than the earnings measure reported by the U.S. Bureau of Economic Analysis (BEA) through its county personal income program. Information for industries not covered by UI programs, the incomes of the self-employed, and other labor income are excluded from our data. The BEA information is annual data available only since 1965 . Quarterly data provide an opportunity to study very shortrun trends at the local level, and are available from $1961 .^{5}$

\section{Short-Run Forecasts}

The regression models estimated using data from 1961Q1 through 1979Q4 are presented in Table 1. Note that derivative wage and salaries are the dependent variable in each equation. The "multiplier" is, therefore, equal to one plus the estimated coefficient on basic wages and salaries.

The regression estimates presented here are consistent with earlier findings for these communities conceming city size and the hierarchy of cities. Specifically, the "multipliers" for the two Montana communities are greater than those for the Oregon communities even though the populations of Missoula and Flathead Counties are much less than those of Linn-Benton and Douglas Counties. An earlier study suggested that trade centers may have greater propensities to spend locally and may be higher in the hierarchy of cities than the population indicates (Polzin and Schallau, 1983).

All four of the regressions have high $\overline{\mathbf{R}^{2}}$ and low standard errors for the estimated parameters. However, the Durbin-Watson (D-W) statistics indicate serial correlation of the residuals for all communities, except Linn-Benton Counties. Serial correlation invalidates many of the standard tests of statistical significance because the reported standard errors may be too small.

The Cochrane-Orcutt technique was used to correct for autocorrelation in each specification with a significant D-W statistic. This procedure was either unsuccessful in eliminating the serial correlation or led to noticeably infe- 
Table 1

Estimated Regression Models for Four Timber-Dependent Communities, 1961Q1 through 1979Q4

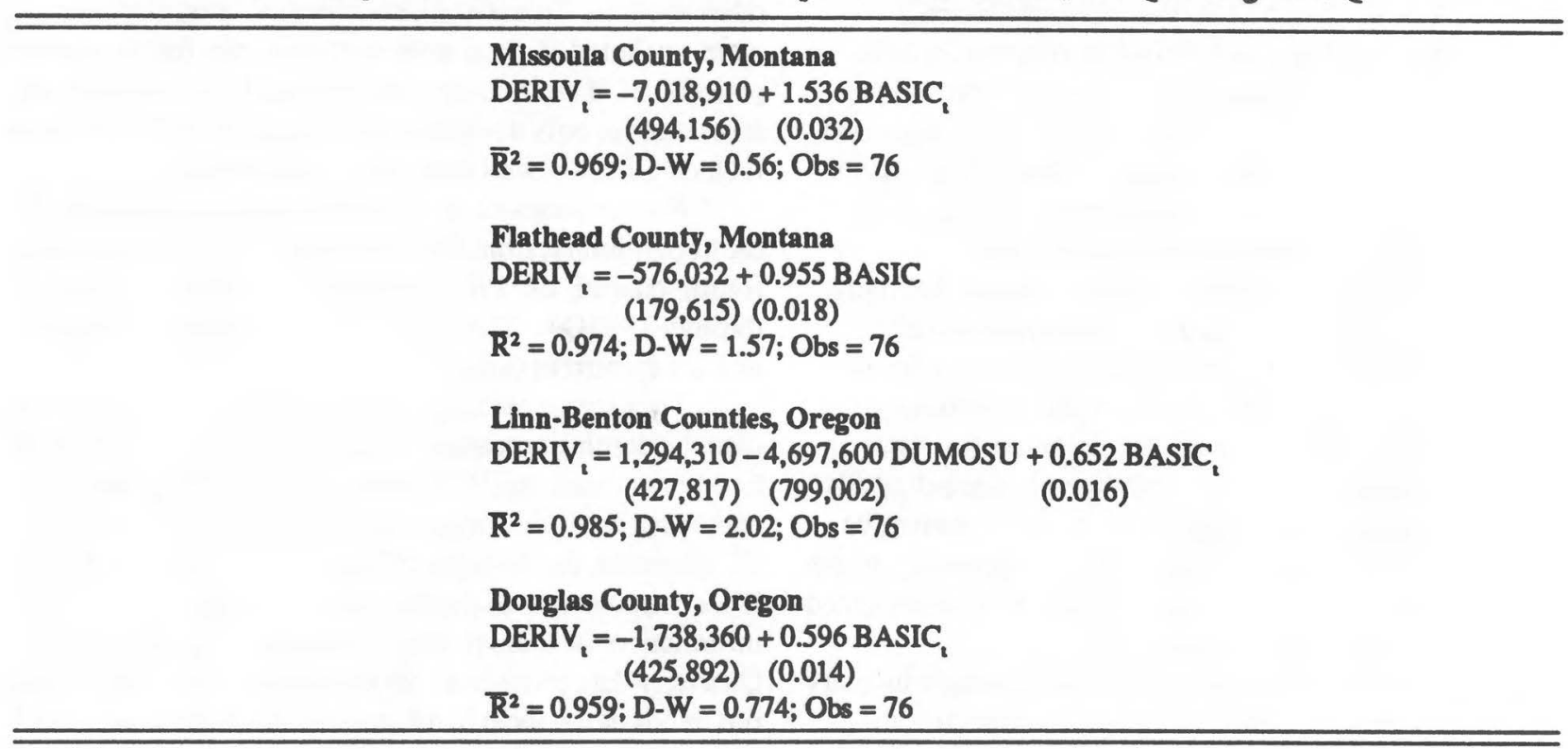

where: DERIV = total wages and salaries in derivative industries;

BASIC = total wages and salaries in basic industries;

DUMOSU = 0 for 1961Q1 to 1971Q4; and

DUMOSU = 1 for 1972 Q 1 to 1979 Q4.

Note: Numbers in parentheses are the standard errors for the corresponding coefficients.

rior forecasts. Because of the emphasis in this study on outof-sample forecasting, the presence of autocorrelation, or other maladies associated with a low D-W value, may not warrant as much concern as in other research. When parameter value changes are examined later in this paper, it is noted that downward biases in the standard errors actually may increase the statistical significance of these tests.

Forecast values for derivative wages and salaries between 1980Q1 and 1984Q4 were calculated for each community by inserting the appropriate values for basic wages and salaries into the equations. This forecast period included two national recessions (1980 and 1981-82), unprecedented high interest rates, and the beginning of a strong and sustained economic recovery. Timber-dependent communities are very sensitive to national business cycles. The extreme volatility of the 1980-84 period makes it a rigorous test of the economic base model. The actual and the forecast values for derivative wages and salaries are graphed in Figures 2 to 5 .

Because no single criterion for "good" projections exists, the forecasts were evaluated in three ways. First, the actual and projected values were compared visually using graphical analysis. Second, the out-of-sample mean absolute percent error (MAPE) for each community was com- pared with the in-sample MAPE. If the two were roughly equal, errors during the forecast period were about equal to those of the estimation period, suggesting that no sizeable parameter changes had occurred. A much larger out-ofsample MAPE may be associated with structural changes causing deteriorating accuracy. Third, the short-run forecasts for derivative wages and salaries in each community were evaluated using Theil's $U$ statistic.

The actual and projected values for derivative wages and salaries and diagnostic statistics for each community are presented in Figures 2 to 5. A visual analysis of the graphs reveals that (1) the general trend in the predicted derivative wages and salaries closely follows actual data trends; (2) seasonal patterns are similar in both series, suggesting that seasonal variations in the basic industries are a major determinant of those in derivative industries; ${ }^{6}$ and (3) the serial correlation of the errors observed during the estimation period continued in the forecast period, as reflected by persistent under- or overestimation in all the communities.

The diagnostic statistics generally confirm the good forecasting performance pictured in the graphs. The outof-sample MAPEs for all of the communities were roughly equal to those for the estimation period. The approximate 


\section{Figure 2}

Derivative Wages and Salaries for Missoula County, 1980-1984

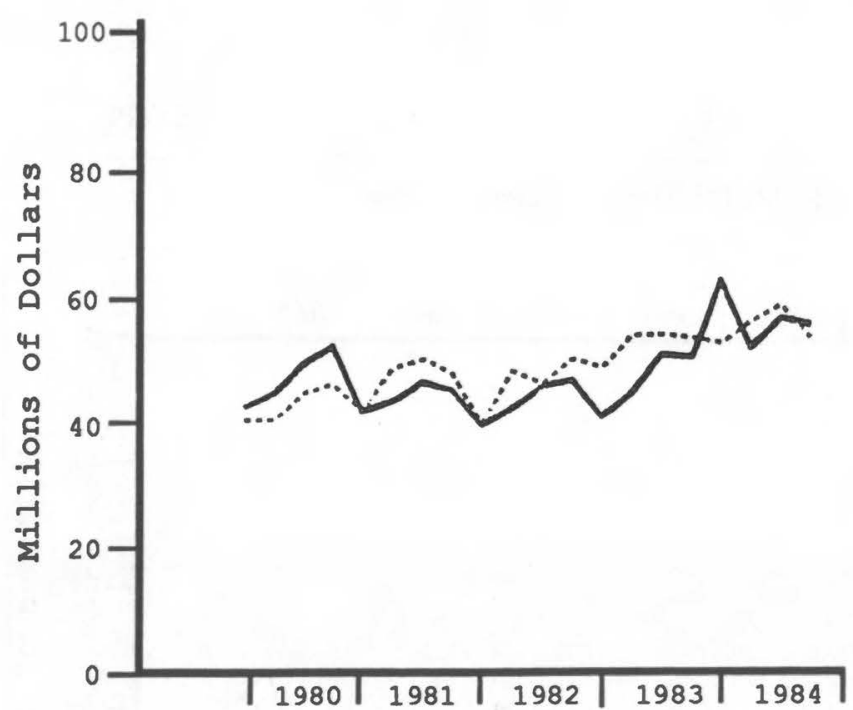

\begin{tabular}{lcc} 
& $1980 \mathrm{Q} 1-1984 \mathrm{Q} 4$ & $1961 \mathrm{Q} 1-197904$ \\
\hline MAPE & 8.0 & 12.6 \\
Theil's $U$ & 0.047 &
\end{tabular}

Percent due to:

Bias

Variation

Covariation

4.9

0.7
94.4
Actual

Projected

- I. I.
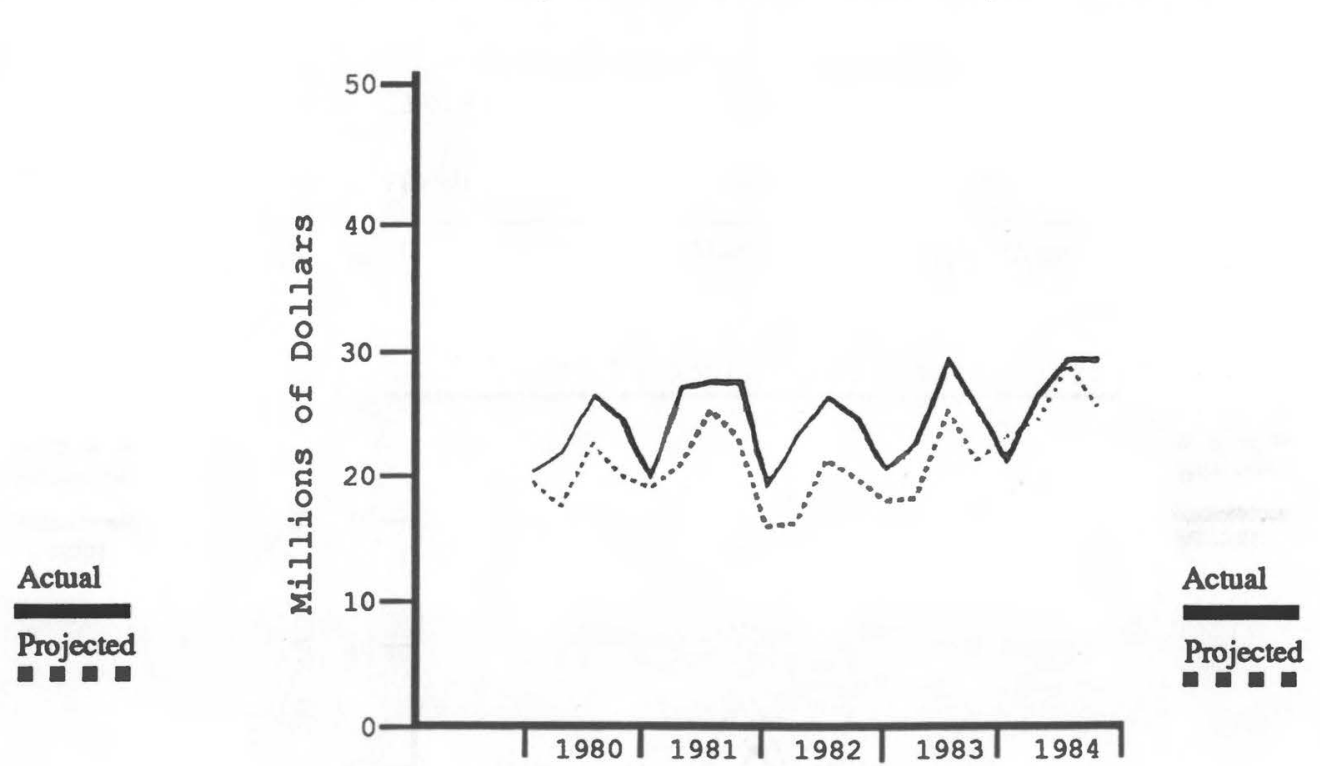

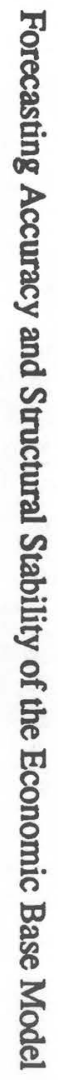

Percent due to:

Bias $\quad 58.4$

Variation

0.1

Covariation

415 
Figure 4

Derivative Wages and Salaries for Linn-Benton Counties, 1980-1984

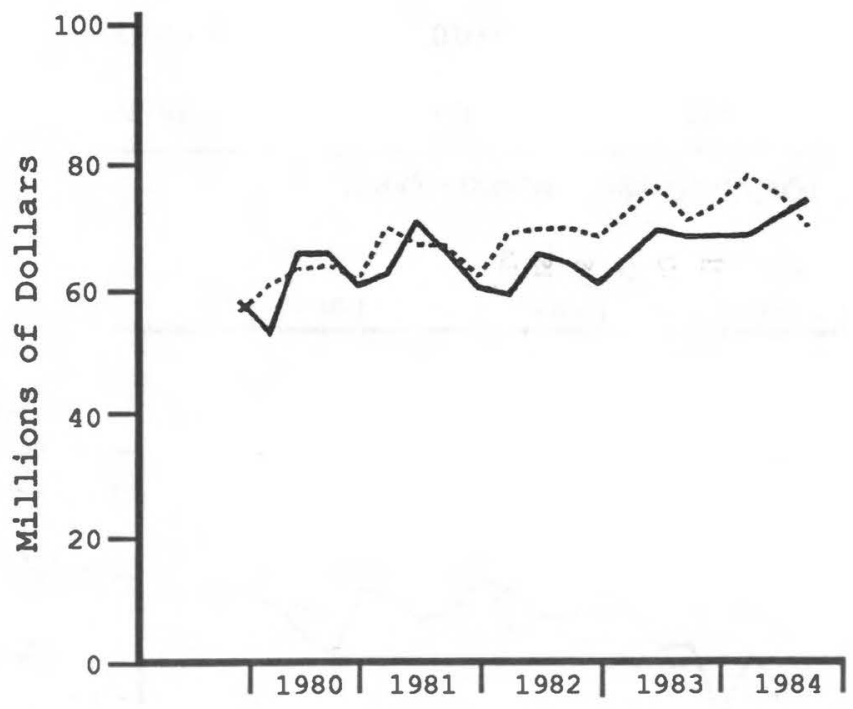

1980Q1-1984Q4 1961Q1-1979Q4

\begin{tabular}{lr}
\hline MAPE & 7.4 \\
Theil's $U$ & 0.041 \\
& \\
Percent due to: & \\
$\quad$ Bias & 37.7 \\
Variation & 4.8 \\
Covariation & 61.7
\end{tabular}

Figure 5

Derivative Wages and Salaries for Douglas County, 1980-1984

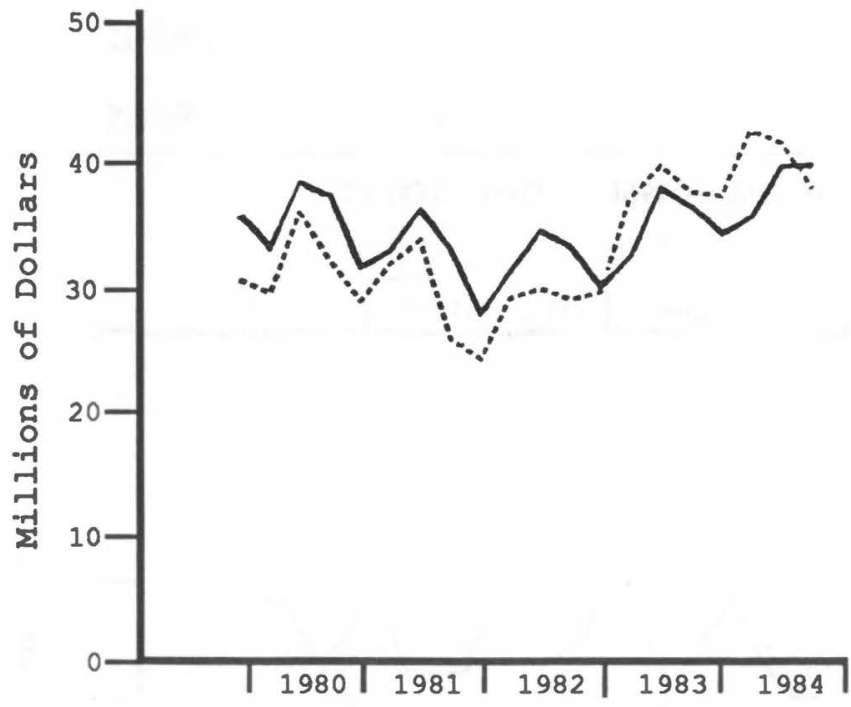

Actual

Projected

- iv

1980Q1-1984Q4

1961Q1-1979Q4

\begin{tabular}{ll}
\hline MAPE & 9.6 \\
Theil's $U$ & 0.054 \\
& \\
Percent due to: & \\
$\quad$ Bias & 12.0 \\
Variation & 26.0 \\
Covariation & 61.0
\end{tabular}


equality of the MAPEs suggests that there were no significant deteriorations in the performance of the models between the estimation period and the forecast period, and no sizable changes in the parameters.

Values for Theil's $U$ statistic were computed for the forecast period and are reported in Figures 2 to 5. Theil's $U$ is a measure of forecasting accuracy and has values $0 \leq$ $U \leq 1$. The lower the value of $U$, the more accurate the forecast. There are no commonly accepted standards for Theil's $U$ that indicate a "good forecast," but values of 0.30 or less have been labeled "not large" (Pindyck and Rubenfeld, 1981).

The value of Theil's $U$ may be decomposed into components that measure various characteristics of the forecasts (Pindyck and Rubenfeld, 1981). Specifically:

$$
\begin{aligned}
& \text { Bias = the percent of Theil's } U \text { due to } \\
& \text { Variance }=\text { the percent of Theil's } U \text { due to }
\end{aligned}
$$

The values of Theil's $U$ statistics in all four communities lie between 0.041 and 0.060 , suggesting that the overall forecasting performances are roughly similar. A closer look at the components, however, reveals a slightly different story. The bias and variation components are low for Missoula County, and the covariation component was about 95 percent, suggesting that few improvements are possible to improve the forecasting performance of this model (Koutsoyiannis, 1977).

Flathead and Linn-Benton Counties have relatively large bias components: about 58.4 percent in the former and 37.7 percent in the latter. These can be attributed to systematic differences between the actual and projected series, perhaps reflecting the persistent underestimation shown in Figure 3 and the overestimation depicted during the latter portion of the forecast period in Figure 4. The sizable variance component in Douglas County indicates unequal fluctuations in the actual and projected series.
In summary, the simplest specification of the economic base model provided acceptable forecasts in all of the four timber-dependent communities. An analyst making forecasts for 1980 to 1984 would have experienced errors roughly equal to those of the estimation period, assuming that he had correctly anticipated the values of BASIC.

\section{Longer-Run Forecasts}

The forecasting performance of the economic base model over a longer period was evaluated in a manner similar to that used for the short run. An economic base specification was estimated for each community using data for 1961Q1 through 1973Q4, and forecasts were made from 1974Q1 through 1984Q4. The actual and forecast value of derivative wages and salaries are presented in Figures 6 to 9.?

It takes only a quick glance at Figures 6 to 9 to determine that the longer-run forecasting performance of the economic base model was somewhat less impressive than its short-run performance. In all of the counties except Linn-Benton, wages and salaries were persistently underestimated.

In Missoula, Flathead, and Douglas counties, the diagnostic statistics confirm the graphical impression. First, the out-of-sample MAPEs in each of these communities were generally larger than the in-sample MAPEs. Missoula and Flathead counties had out-of-sample MAPEs roughly one-third to one-half larger than the insample MAPEs. In Douglas County, the out-of-sample MAPE was more than three times its in-sample counterpart.

Second, Theil's $U$ statistics computed for longer-run forecast period (1974Q1 through 1984Q4) generally were larger than the corresponding figures for the short-run forecast period (1980Q1 through 1981Q4). The value of Theil's $U$ increased about 15 percent in Flathead County ( 0.060 versus 0.069$)$, nearly doubled in Missoula County ( 0.047 versus 0.087$)$, and more than doubled in Douglas County ( 0.054 versus 0.123$)$.

Finally, the bias components of Theil's $U$ in Flathead, Missoula, and Douglas counties varied from 50 to 80 percent, indicating systematic differences between the actual and forecast series. This, of course, simply reflects the persistent underestimation pictured in the graphs.

Only Linn-Benton Counties had favorable values for the diagnostic statistics. The out-of-sample MAPE was roughly equal to the in-sample MAPE (5.2 percent versus 6.2 percent), indicating very little deterioration in forecasting performance between the estimation and projection 


\section{Figure 6}

Derivative Wages and Salaries for Missoula County, 1974-1984

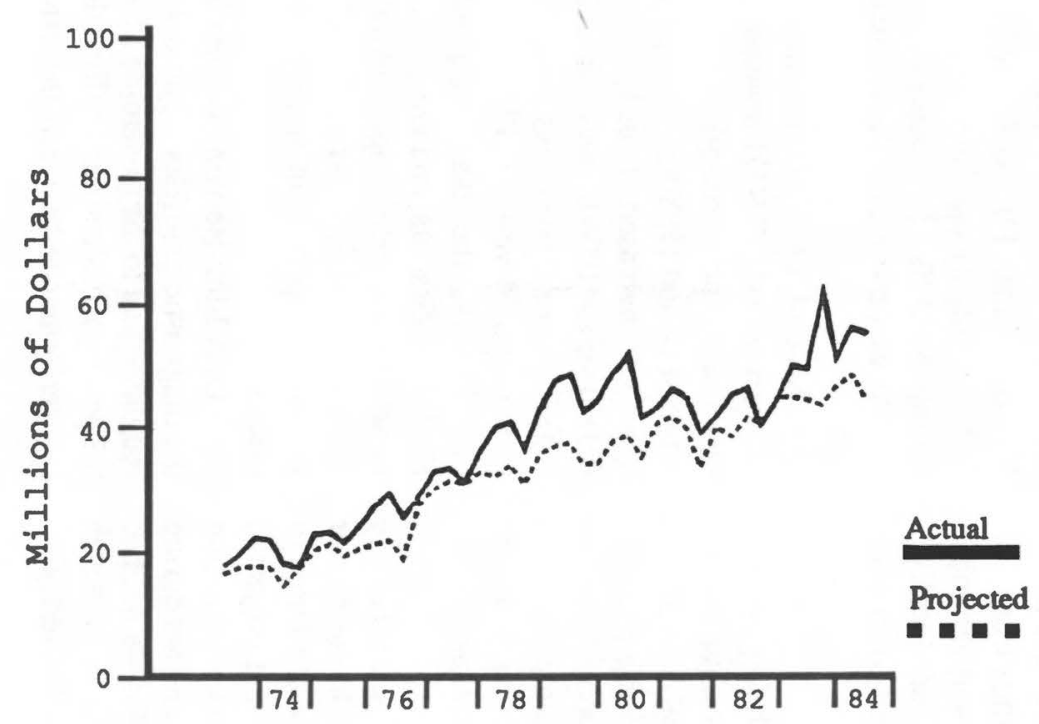

1974Q1-1984Q4 1961Q1-1973Q4

\begin{tabular}{lr} 
& 1974Q1-1984Q \\
\hline MAPE & 13.6 \\
Theil's $U$ & 0.087 \\
& \\
Percent due to: & \\
$\quad$ Bias & 66.5 \\
$\quad$ Variation & 7.9 \\
Covariation & 25.5
\end{tabular}

Figure 7

Derivative Wages and Salaries for Flathead County, 1974-1984

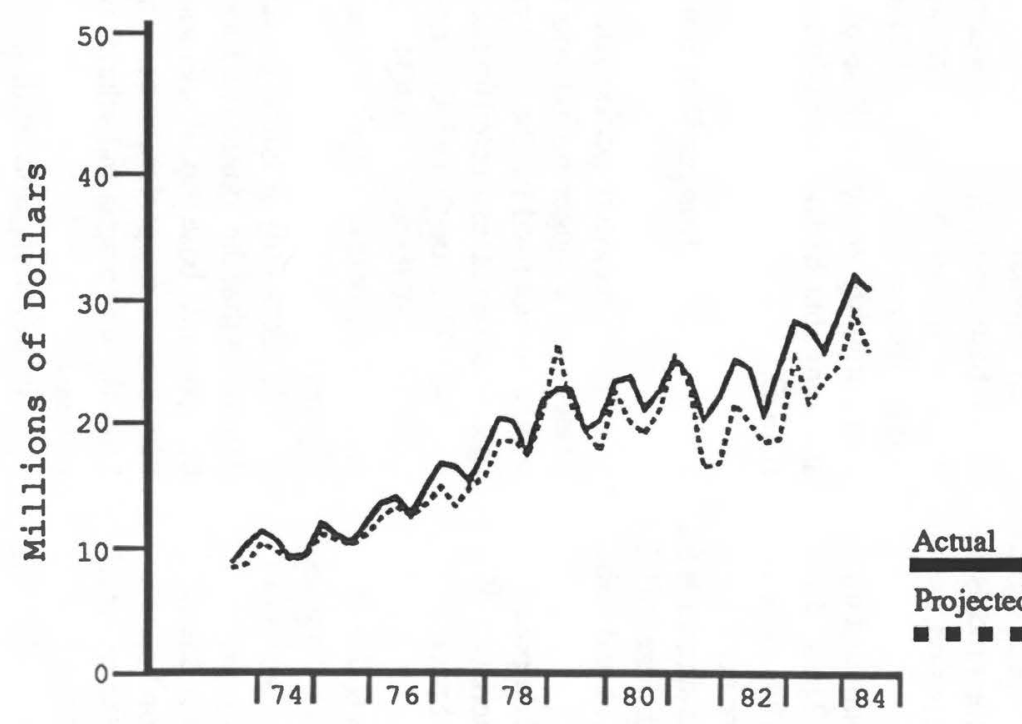

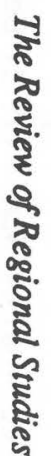

\begin{tabular}{lr} 
& 1974Q1-1984 \\
\hline MAPE & 9.8 \\
Theil's $U$ & 0.069 \\
& \\
Percent due to: & \\
Bias & 50.0 \\
Variation & 9.2 \\
Covariation & 40.8
\end{tabular}




\section{Figure 8}

Derivative Wages and Salaries for Linn-Benton Counties, 1974-1984

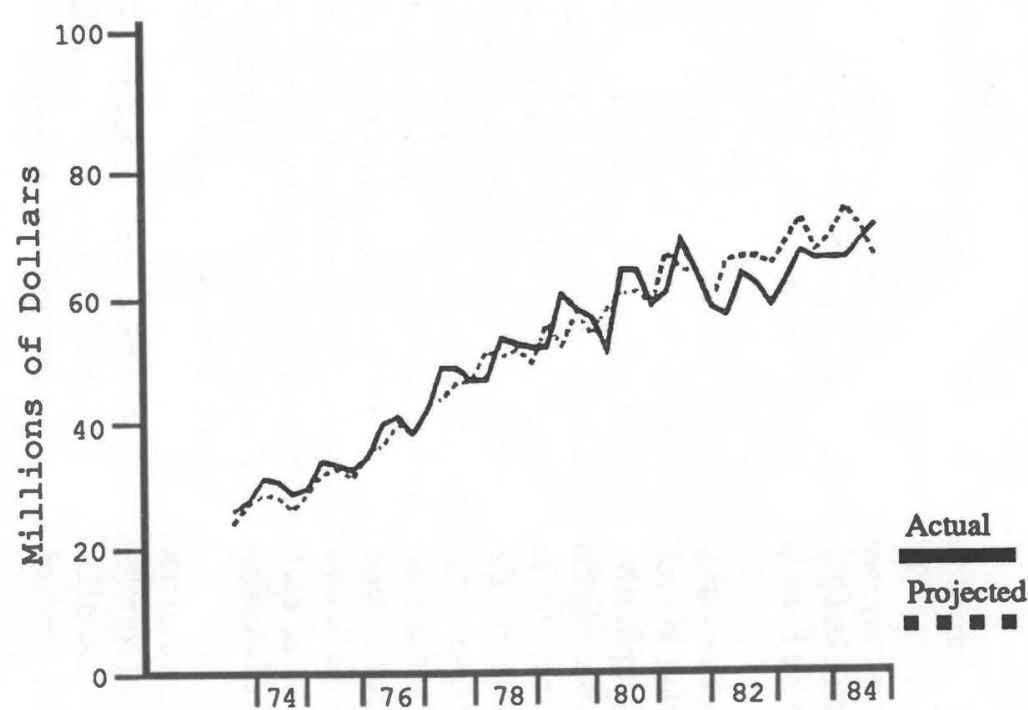

$1974 Q 1-1984 Q 4$

1961Q1-1973Q4

\begin{tabular}{lr}
\hline MAPE & 5.6 \\
Theil's $U$ & 0.035 \\
& \\
Percent due to: & \\
Bias & 0.5 \\
Variation & 14.9 \\
Covariation & 84.7
\end{tabular}

Figure 9

Derivative Wages and Salaries for Douglas Counties, 1974-1984

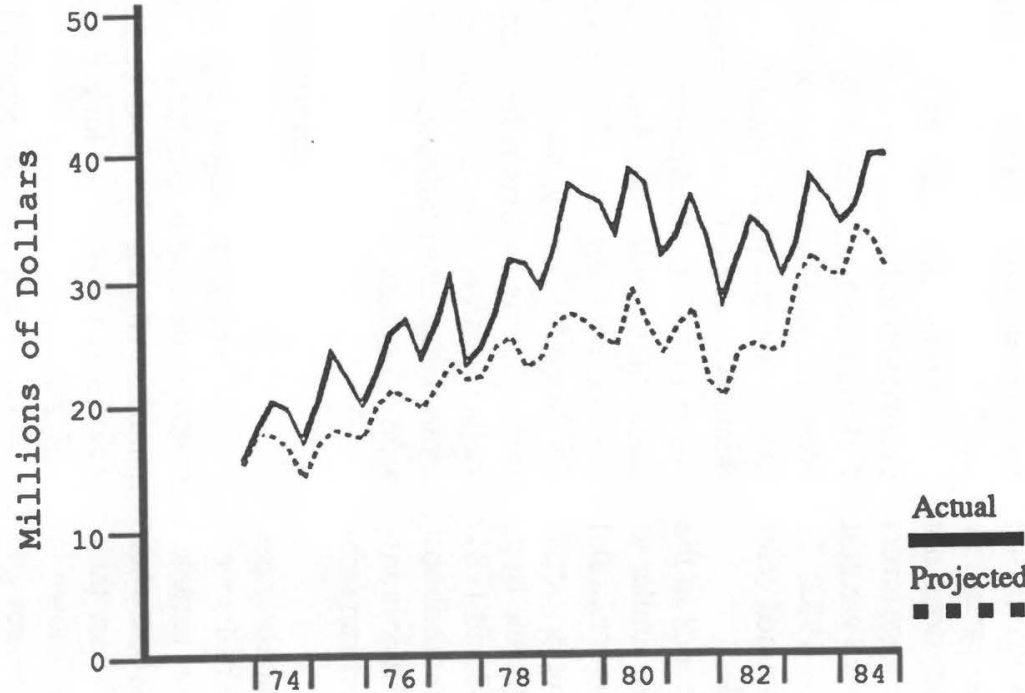

1974Q1-1984Q4 1961Q1-1973Q4

\begin{tabular}{lr}
\hline MAPE & 19.1 \\
Theil's $U$ & 0.123 \\
& \\
Percent due to: & 79.1 \\
Bias & 7.6 \\
Variation & 13.3 \\
Covariation &
\end{tabular}


periods. Theil's $U$ was a respectable 0.035 , with only 4.6 percent attributable to bias and 14.9 percent to variation.

The relative size of the forecast errors does not appear to be growing without limit. The percentage errors in Flathead and Douglas counties generally were greatest during the recession years of 1980,1981 , and 1982. In Missoula County, the percentage errors remained relatively constant throughout the forecast period.

Aside from the systematic errors, the trends in the forecasts for derivative wages and salaries are similar to those in the actual data. ${ }^{8}$ In all communities, the actual and predicted series display the same cyclic patterns: rapid growth in the late 1970s, stagnation and/or decline from 1980 to 1982, and then a recovery during 1983 and 1984. Also, the seasonal patterns in the forecast series are almost identical to those of the actual, indicating that basic industries are the major determinant of the very short-run (seasonal) variations in derivative industries.

Finally, the shortcomings of the longer-run forecasts must be tempered by the fact that the predictions lie well outside of the range of values on which the model parameters were estimated. Regression models forecast best when the independent and dependent variables are near their respective sample means (Kmenta, 1971). As shown in Figures 6 through 9, the value of derivative wages and salaries roughly tripled in all four communities from 1974 through 1984. Therefore, the predicted values are all much larger than their respective means during the estimation period.

What caused the underestimation of derivative wages and salaries in three of the four communities? The economic base specification estimated here has only two parameters, the constant term and the slope coefficient (the multiplier). If there was instability, it must have been in one of these two parameters.

Table 2 presents information needed for examining the stability of the economic base specification in each community. A combination of additive and multiplicative dummy variables was used to estimate simultaneously the constant term and slope coefficients for the two periods. In this specification, the statistical significance of the DUMMY variable indicates a shift in the constant term, while a change in the slope (multiplier) may be analyzed using the $t$-test for a difference in regression coefficients (Johnston, 1972).9 This approach is superior to the "Chow Test," as usually conducted, because it looks at each parameter separately and reveals the magnitude of changes in each.

The standard levels of statistical significance do not apply here, because all four equations have serial correlation of the residuals as indicated by the Durbin-Watson (DW) values. In other words, the estimated standard errors of the constant terms and slope coefficients probably are too small. ${ }^{10}$

Taking into account the downward biases in the estimated standard errors, the regressions reported in Table 2 do not indicate instability of the parameters of the economic base model. The DUMMY variable was significant, using accepted standards $(t=2.21)$, only for LinnBenton Counties. Given the possibilities of the downward biases in the standard errors, this $t$ ratio probably is not statistically significant. Similarly, the test for differences in slope coefficients yielded generally negative results. For Douglas County, the $t$ ratio was about 2.2. Only a modest downward bias in the standard errors could account for this apparent statistical significance. For the remaining communities, the $t$ ratios testing for shifts in the multiplier were 1.3 or less.

\section{Summary}

This paper presented ex post forecasts derived from an economic base model for four timber-dependent communities in the Pacific Northwest. A 20-quarter short-run period and a 44-quarter longer-run forecast period were analyzed.

In the short run, the economic base model provided acceptable forecasts. The short-run forecast period was particularly turbulent in the four study areas and provided a stringent test of the economic base model. From 1980 to 1982, the U.S. economy experienced severe business cycles that had disproportionate impacts on timber-dependent communities.

In the longer run, the performance of the economic base model was less impressive. In three of the four communities, it persistently underestimated the level of derivative activity. Further analysis did not uncover conclusive evidence of instability in the parameters of the underlying model.

Although not statistically conclusive, the persistent underestimation in three of the four study areas suggests shifts in the parameters of the economic base model. A multiplier change is not inconsistent with economic base theory; it can be caused by import substitution and/or agglomerations in the local economy (Green, 1966).

Another potential cause of a change in the multiplier is growth in excluded basic industries. Increases in basic industries or other exogenous activities not included in the analysis may shift the relationship between the basic and derivative sectors. Examples include the following:

A. Non-covered Industries. The data analyzed here included only activities covered by unemployment insurance. Excluded are the 
Table 2

Estimated Regression Models for Four Timber-Dependent Communities, 1961Q1 through 1984Q4

\begin{tabular}{|c|c|c|c|c|c|c|c|c|}
\hline & Constant & DUMMY & $\begin{array}{c}\text { BAS } \\
1961 Q 1- \\
1973 Q 4\end{array}$ & 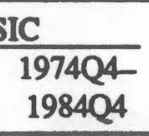 & DUMOSU & $\overline{\mathbf{R}^{2}}$ & D-W & Obs \\
\hline \multicolumn{9}{|c|}{ Missoula County, Montana } \\
\hline Deriv = & $\begin{array}{r}-2,717,650 \\
(1,205,390)\end{array}$ & $\begin{array}{c}812,988 \\
(1,846,880)\end{array}$ & $\begin{array}{c}1.253 \\
(0.114)\end{array}$ & $\begin{array}{c}1.411 \\
(0.047)\end{array}$ & & 0.976 & 1.138 & 96 \\
\hline \multicolumn{9}{|c|}{ Flathead County, Montana } \\
\hline Deriv $=$ & $\begin{array}{l}-477,911 \\
(533,447)\end{array}$ & $\begin{array}{c}-164,542 \\
(816,592)\end{array}$ & $\begin{array}{c}0.914 \\
(0.091)\end{array}$ & $\begin{array}{c}1.001 \\
(0.031)\end{array}$ & & 0.977 & 1.415 & 96 \\
\hline \multicolumn{9}{|c|}{ Linn-Benton Counties, Oregon } \\
\hline Deriv $=$ & $\begin{array}{l}1,401,950 \\
(1,284,690)\end{array}$ & $\begin{array}{c}6,908,020 \\
(3,111,834)\end{array}$ & $\begin{array}{l}0.647 \\
(0.059)\end{array}$ & $\begin{array}{c}0.564 \\
(0.016)\end{array}$ & $\begin{array}{c}-5,443,500 \\
(1,676,150)\end{array}$ & 0.986 & 1.760 & 96 \\
\hline \multicolumn{9}{|c|}{ Douglas County, Oregon } \\
\hline Deriv $=$ & $\begin{array}{c}1,152,750 \\
(889,222)\end{array}$ & $\begin{array}{c}213,529 \\
(1,681,220)\end{array}$ & $\begin{array}{l}0.438 \\
(0.043)\end{array}$ & $\begin{array}{c}0.550 \\
(0.028)\end{array}$ & & 0.966 & 0.840 & 96 \\
\hline
\end{tabular}

where: DERIV = wages and salaries in derivative industries;

BASIC = wages and salaries in basic industries;

DUMMY = 0 for 1961Q1 through 1973Q4;

DUMMY = 1 for 1974Q1 through 1984Q4;

DUMOSU = 0 for 1961Q1 through 1971Q4; and

DUMOSU $=1$ for 1972 Q 1 through 1979 Q4.

Note: Numbers in parentheses are the standard errors for the corresponding coefficients.

self-employed, railroads, and certain other industries. However, the analysis of available BEA data suggests that the addition of these items would not alter significantly the findings reported here;

B. Trade Center Activities. Both Missoula and Flathead counties are trade centers, but no measure of this activity was included in the variable measuring the basic sector. Other information, on the other hand, indicates that trade center activities in both of these communities represent less than 10 percent of the economic base and have not experienced disproportionate growth; and

C. Certain types of Transfer Payments and a portion of Property Income (dividends, interest, and rents) conceptually are similar to export industries, but were not included in this study. Preliminary findings suggest that the inclusion of transfer payments and property income provides only a very limited explanation of parameter instability, and introduce other statistical and analytical problems (Polzin, et al., 1987).

In both the short run and the longer run, the economic base models correctly forecast seasonal and cyclic trends in all the communities. This is contrary to McNulty who concluded that the economic base model was valid only for the long run.

The findings presented here suggest that researchers analyzing specific communities need not be overly concerned about the presence of serial correlation of the residuals or other problems with the sample variance. The simplest specifications, with no corrections for autocorrelation, generally provided the best forecasts.

In summary, these findings give added confidence to researchers using the economic base approach to analyze small communities. Parameters estimated using time series data were relatively stable over both five- and 11year forecasting periods and for predictions well beyond the range of values used for estimation. Also, basic industries were a major determinant of seasonal and cyclic trends in the local economies. On the other hand, there are suggestions that forces may be at work leading to system- 
atic changes in the multiplier. Further research is needed to identify these forces and to determine the conditions for which they may be relevant.

\section{Notes}

${ }^{1}$ Economic impact analysis appears less popular in major metropolitan areas, possibly because the opening or closing of one facility would have only a minor impact on the economy. In addition, major metropolitan areas may be analyzed best using multi-equation econometric models.

2Both Missoula and Flathead counties are regional trade centers (Schallau and Polzin, 1983). The export component of trade, services, and other trade center industries were not included in the basic sector. Current methods for bifurcating these industries rely on location quotients, and may be unreliable for the analysis of time series data. In any case, the trade center functions were relatively small (less than 10 percent of the economic base) and have not grown disproportionately (Schallau and Polzin, 1983 (Tables 2 and 3)).

${ }^{3}$ The following percentages were derived from Schallau and Polzin (1983) and understate the domination of these industries in the data used here. Schallau and Polzin include industries, such as railroads and agriculture, in their basic sector that could not be included in this study because they were not covered by unemployment insurance.

There was a one-time increase in the level of wages and salaries at Oregon State University in Linn-Benton counties during 1972. The Oregon Employment Division could provide no explanation. Some speculate that a group of university employees-such as the Agricultural Extension Divisionbecame covered by unemployment insurance. A dummy variable was used to account for this discontinuity in the data.

'BEA data were used to re-estimate some of the specifications reported later. The results suggest that the omission of self-employment and other labor income, the income earned in non-covered industries, plus the exclusion of industries that had a change in UI coverage, did not seriously degrade the data. Details are available upon request from the authors.

${ }^{6}$ Specifications using seasonal dummy variables were estimated for each community. In general, these dummy variables were not statistically significant, nor did they improve the forecasting ability of the models.

'In the interest of brevity, the forecasting models are not presented. The estimated parameters used to derive the forecasts are numerically identical to those for the constant term and the 1961Q1-1973Q4 coefficient on BASIC presented in Table 2.

During 1979 in Flathead County there was a sharp increase in predicted derivative wages and salaries due to a large, one-time rise in basic wages and salaries. The movie "Heaven's Gate" was filmed in various nearby locations. Many local residents were hired as extras and for other duties. The lack of a corresponding increase in actual derivative wages and salaries suggests that this event did not have further effects on the local economy.

The estimated equation is as follows: where

$$
\text { DERIV }=a+a D_{2}+b_{1}\left(D_{1} \text { BASIC }\right)+b_{2}\left(D_{2} \text { BASIC }\right),
$$

$$
\begin{aligned}
D_{1} & =1 \text { for } 1961 Q 1 \text { through } 1973 Q 4, \\
& =0 \text { for } 1974 Q 1 \text { through } 1984 Q 4, \\
D_{2} & =0 \text { for } 1961 Q 1 \text { through } 1973 Q 4, \text { and } \\
& =1 \text { for } 1974 Q 1 \text { through } 1984 Q 4 .
\end{aligned}
$$

${ }^{10}$ In addition, there is heteroscedasticity of the residuals in each equation, and this also would bias downward the estimates of the standard errors.

\section{References}

Bender, Lloyd D., and Larry C. Parcels. "Structural Differences and the Time Patterns of Basic Employment." Land Economics. 59:2 (May 1983). 220-234.

Connaughton, Kent, Paul E. Polzin, and Con Schallau. "Tests of the Economic Base Model of Growth for a Timber Dependent Region." Forest Science. 31:3 (August 1985). 717-725.

Garrison, Charles B. "The Impact of New Industry: An Application of the Economic Base Multiplier to Small Rural Areas." Land Economics. 48:2 (November 1972). 329-337.

Giarratani, Frank, and Paul D. McNelis. "Time Series Evidence Bearing on Crude Theories of Regional Growth." Land Economics. 56:2 (May 1980). 283-348.

Green, George R. "Community Size and Agglomeration of Trade, Services, and Other Locally Oriented Industries." Working Paper CWR5. St. Louis, Mo.: Washington University Institute for Urban and Regional Studies, 1966.

Henry, Mark S., and J. C. O. Nyankori. "The Existence of Short-Run Economic Base Multipliers: Some New Evidence." Land Economics. 57:3 (August 1981). 448-458.

Hildebrand, George H. and Arthur Mace, Jr. "The Employment Multiplier in an Expanding Industrial Market, 19401947." The Review of Economics and Statistics. 32 (August 1950). 141-149.

Johnston, J. Econometric Methods. New York: McGraw-Hill Book Co., 1972.

Koutsoyiannis, A. Theory of Econometrics. London: The Macmillan Press Ltd., 1977.

Kmenta, Jan. Elements of Econometrics. New York: The Macmillan Co., 1971.

Lane, Theodore. "The Urban Economic Base Multiplier: An Evaluation of the State of the Arts." Land Economics. 32:3 (August 1966). 339-347.

Luttrell, Clifton B., and C. M. Gray. "Metropolitan Area Growth: A Test of Export Base Concepts." Review of the Federal Reserve Bank of St. Louis. Reprint Series No. 58 (July 1970). 1-17.

McNulty, James E. "A Test of the Time Dimension in Economic Base Analysis." Land Economics. 53:3 (August 1977). 359-368. 
Pindyck, Robert S., and Daniel L. Rubenfeld. Econometric Models and Economic Forecasts. New York: McGrawHill Book Co., 1981.

Polzin, Paul E. "Urban Employment Models: Estimation and Interpretation." Land Economics. 49:2 (May 1973). 226-232.

- "Urban Labor Markets: A Two Sector Approach." Growth and Change. 8:1 (January 1977). 11-15.

and Con H. Schallau. "Characterizing Economic

Trends in Small Resource-Dependent Communities." The

Southwestern Review of Management and Economics. 3:2 (Spring 1983). 85-95.

Kent Connaughton, Con H Schallau, and James T.
Sylvester. "Transfer Payments and Property Income as Sources of Economic Growth in the Pacific Northwest." Paper Presented at the 21st Annual Meeting of the Pacific Northwest Regional Economic Conference, Seattle, Wash., May 1987. Reprinted in the Conference Proceedings.

Schallau, Con H, and Paul E. Polzin. Considering Departures from Current Timber Policies: Case Studies of Four Communities in the Pacific Northwest. Research Paper PNW. 306. Portland, Ore.: USDA Forest Service, Pacific Northwest Forest and Range Experiment Station, 1983.

Thompson, Gerald Everett. "An Investigation of the Local Employment Multiplier." The Review of Economics and Statistics. 41:1 (1959). 1-67.

Tiebout, Charles M. The Community Economic Base Study. New York: The Committee for Economic Development, 1962.

\section{Appendix Table 1}

\begin{tabular}{ll}
\hline \multicolumn{1}{c}{ Export Industries for Flathead County, Montana } \\
\hline Industry & SIC Code \\
\hline Agricultural Services, Forestry, and Fisheries & $07-09$ \\
Mining & $10-14$ \\
Lumber and Wood Products & 24 \\
Furniture and Fixtures & 25 \\
Primary Metals Refining & 33 \\
Transportation Equipment & 37 \\
Hotels, Rooming Houses, Camps, and Other Lodging Places & 70 \\
Federal Civilian & - \\
\hline \hline
\end{tabular}

Appendix Table 2

Export Industries for Missoula County, Montana

Industry

Agricultural Services, Forestry, and Fisheries

Mining

Apparel

Lumber and Wood Products

Fumiture and Fixtures

Pulp and Paper Products

Chemicals and Allied Products

Stone, Clay, and Concrete Products

Transportation by Air

Hotels, Rooming Houses, Camps, and Other Lodging Places

Educational Services, State Government (University of Montana)

SIC Code

07-09

10-14

23

24

25

26

28

32

45

70

822 
Appendix Table 3

Export Industries for Douglas County, Oregon

\begin{tabular}{ll}
\hline Industry & SIC Code \\
& \\
Agricultural Services, Forestry, and Fisheries & $07-09$ \\
Mining, except Quarrying & $10-13$ \\
Meat Products & 201 \\
& \\
Canned and Preserved Fruits and Vegetables & 203 \\
Miscellaneous Food Preparation (fish) & 209 \\
Lumber and Wood Products & 24 \\
& 26 \\
Pulp and Paper Products & 33 \\
Primary Metals Refining & 35 \\
Machinery, Except Electrical & 70 \\
Hotels, Rooming Houses, Camps, and Other Lodging Places & - \\
Federal Civilian & \\
\hline \hline
\end{tabular}

Appendix Table 4

Export Industries for Linn-Benton Counties, Oregon

Industry

Agricultural Services, Forestry, and Fisheries

Mining, except Quarrying

Meat Products

Canned and Preserved Fruits and Vegetables

Grain Mill Products*

Miscellaneous Food Preparation*

Lumber and Wood Products

Fumiture and Fixtures

Pulp and Paper Products

Primary Metals Refining*

Fabricated Metal**

Machinery, Except Electrical

Electrical Machinery*

Hotels, Rooming Houses, Camps, and Other Lodging Places 70

Educational Services, State Government (Oregon State University)* 822

Engineering, Architectural, and Surveying Services* 891

\section{SIC Code}

07-09

10-13

201

203

204

209

24

25

26

33

34

35

36

22

Federal Civilian

*Linn County only

**Benton County only 